\title{
The Perceptions of Students on the Implementation of Peer Academic Support Programmes at One University in South Africa
}

\author{
Magdaline Nji Tangwe \\ Faculty of Education, University of Fort Hare \\ PB X1314, Alice 5700, South Africa \\ Email: njimado@yahoo.com \\ Professor S. Rembe \\ Faculty of Education, University of Fort Hare \\ PB X1314, Alice 5700, South Africa \\ Email: srembe@ufh.ac.za
}

Doi:10.5901/mjss.2014.v5n4p378

\begin{abstract}
The general concern regarding the high dropout and low throughput rates at previously disadvantaged universities led to the establishment of academic support programmes. The paper examines the perceptions of undergraduate students regarding the implementation of the supplemental instruction and language and writing consultant programmes at one university in South Africa. The findings reveal that these programmes are very useful and helpful to undergraduate students though there are some shortcomings that need the attention of the administration of the university. In this regards, some recommendations are presented in order to ameliorate the implementation of these cherished programmes.
\end{abstract}

Keywords: peer academic support programmes, disadvantaged universities, peer assisted student services, teaching and learning centre

\section{Introduction}

The White Paper on Higher Education (Act No: 101 of 1997) outlines a comprehensive set of initiatives for the transformation of higher education through the development of a single co-ordinated system (Department of Higher Education, 1997). Many institutions at the tertiary level have instituted measures and programmes to redress the inequality of the past as reflected in the White Paper (1997) to help students cope and succeed in higher education/university learning. Some higher education institutions in attempts to reach this goal of redressing the past educational imbalances and transform the higher educational sector opted for Senate Discretionary Exemption Policy and Recognition of Prior Learning Policy particularly previously disadvantaged universities (Department of Higher Education Training, 2012). These policies enable students who do not meet the entry requirements for a degree to be deliberately admitted irrespective of their weak Matriculation results (Makura, Skead \& Nhundu, 2011). The aim of these policies is to increase academic access to higher education or what is commonly called massification of higher education (Cloete \& Bunting, 2000).

These policies have led to the admission of students who are under-prepared for university study (Department of Higher Education and Training, 2012). It is argued that traditional student market for the previously disadvantaged universities is from provinces that are characterized by poor socio-economic development, poor performance in Matriculation over the years, high poverty level as well as poor infrastructure (Makura, Skead \& Nhundu, 2011:15). These historical factors have impacted negatively on student throughput and retention rates at the university level with about $34 \%$ of students failing to complete their programmes in record time (Matomela, 2010). Second language and a lack of a solid foundation at the secondary education are some of the reasons advanced for this poor academic performance (Skead, 2006). According to Peterson and Arends (2009:107), throughput serves as indicator of the efficiency in educational institutions and shows the extent to which students are able to complete their programmes in more or less than the optimal or expected time. Graduation rate is the number of graduations divided by the total number of enrolments within the entire programme in the same year (Subotzky, 2003). It therefore serves as a measure of the rate 
at which students graduate from the institution in which they enrolled.

In an attempt to increase students' retention and throughput rates, most universities in South Africa (particularly historically disadvantaged universities) have established academic support programmes within centres of learning. As McInnis et al. (2000) stressed, students entering a system of higher education for the first time, particularly those whose previous school performance was poor, need help and support with the transition and enculturation process. Reyes (2007) concludes that academic support programmes are vital resources in assisting students to overcome obstacles and aid in students' retention. Reyes (2007:221) emphasized that these programmes occupy a unique place in the structure of an institution because of their "mandate to address the needs and interests of the entire academic community in support of the education of students."

Peer academic support programmes are based on "supplemental instruction principles and processes that integrate academic initiatives" whose aim is to provide academic support to students in the areas of language and writing as well as subject matter seen as difficult (Skead 2006 cited in Makura, Skead \& Nhundu, 2011:16). The model adopted for these programmes is a peer collaborative and active learning one. According to Martin and Arendale (1994), SI was developed in 1970s at the University of Missouri-Kansa City, USA and now serves as an international model of SI programming. In South Africa, SI was established in the early 1980s in response to the need of some black students seeking admission into previously white universities and these programmes were then called 'Academic Support', 'Academic Development', 'Institutional Development' (Boughey, 2010:4). According to Twalo (2008:3) the aim of Supplemental Instruction (SI) is to provide support to students on historically difficult subjects such as natural sciences and accounting through focusing on helping the students to understand the subject content and enable students to be involved in process learning. SI peer facilitators are called Supplemental Instruction Leaders (SIL) who are senior undergraduate students. These facilitators support students facing problems in their subject areas. The facilitators work hand-in-hand with lecturers whose students bring problems to the programme and attend the lecturers' classes and agree on what issues the facilitators should help students (Martin \& Arendale, 1994). Facilitators concentrate on students as individuals as well as groups (Skead, 2006). It is believed that this idea will help the students to co-operate and share ideas as Fisher (1995) indicates that learning with a partner, sometimes called peer tutoring or with a group can extend opportunities in students especially with less able and more able students, when they learn and teach each other. Hence, $\mathrm{SI}$ is non-remedial, proactive, peer-collaborative and active learning whose quality is assured by staff and peer observations. Peer facilitators are provided with extensive ongoing training sessions to ensure that they provide quality guardianship to their peers. They are expected to keep a portfolio of activities for their self-evaluation and reflection (Makura, Skead \& Nhundu, 2011).

Also, according to Archer (2010) some peer programmes target historically disadvantaged students who are in need of academic assistance with writing so as to gain discipline specific conventions. Most often, these facilitators are postgraduate students who have been trained on how to review students' assignments (Cuseo, 2002). In a nutshell, the general structure of an essay should be well-presented before the student submits to the lecturer. Kaburise (2010) notes that the level of language sophistication demonstrated in writing samples by potential university students is below the threshold considered basic for successful tertiary level education. Fourie and Alt (2000:117) similarly indicated that "because many of the 'new' students are first-generation university students, who often come from deprived socioeconomic circumstances, they find it difficult to cope with the demands of the university life." Also it has been noticed that in some institutions, the dropout rate is as high as 80\% (Letseka \& Maile, 2008 cited in Kaburise, 2010). This low success rate mostly comes from students who generally are from disadvantaged communities (Kaburise, 2010). Hence, the need for some kind of intervention to improve, measure and ensure effective and efficient learning by students. Therefore, peer academic support programmes are expected to play a key role as a change agent and provide support to learning activities of students.

However, despite the attempts of the implementation of this peer academic support programmes to ensure retention and throughput, there are still concerns from stakeholders about retention and throughput rates (Jansen, 2012). According to the Department of Higher Education and Training (2012:1), "the high drop-out rate of students in their first year of study revealed through an analysis of specific cohorts is disconcerting." Students who enrolled in 2005 in the university sector were tracked by the Department of Higher Education and Training (2012) throughout their studies until they graduated or dropped-out. The study revealed startling statistics; "drop-out rates for first time entering students in a 3 year qualification are on average $26 \%$ and in the first year, with a further $9 \%$ in the second year and $6 \%$ in the third year, while for a 4-year qualification, the average drop-out rates for first time entering students are $15 \%$ in the first year, with a further $7 \%$ in the second year, $4 \%$ in the third year and 3\% in the fourth year" (Department of Education and Training, 2012:1). It is further indicated that the high drop-out and repetition rates "results in universities losing potential 
state income within the teaching output sub-block grants where graduates in undergraduate programmes are funded.

\section{Statement of the Research Problem}

The overall aim of peer academic support programme implementation is to improve students' academic performance through the provision of necessary academic support which in turn will lead to increase throughput and retention rates. However, these programmes have failed to yield the expected results because the number of students who drop out remains high with high failure rate (OECD, 2008 cited in Chabaya et al, 2010; Letseka and Maile, 2008 cited in Kaburise, 2010; Bally, 2007, Matomela, 2010). This is characterized by poor academic writing and performance in tests, assignments and examinations with only $34 \%$ of students being able to complete their programmes within the stipulated time (Bally, 2007). Hence, the need to examine how peer academic support programmes aimed at supporting students academically to improve academic performance and to ensure retention and throughput at are being implemented. Therefore, this paper seeks to examine students' perceptions vis-à-vis the implementation of peer academic support programmes at one university in South Africa. In other words, the question that this paper attempts to answer is What are the perceptions of students towards the implementation of peer academic support programmes?

\section{Methods}

This section of the paper covers the research approach; population, sample and sampling strategy; instrument of data collection and methods of data analysis as well as ethical consideration.

\subsection{Research Approach: Qualitative}

This study adopted a qualitative research approach. Creswell (2007) explains that the aim of qualitative research approach is to explore and understand a central phenomenon. This has to do with understanding the processes, social and cultural contexts which work in line with various behavioral patterns. The behavioural patterns are mostly concerned with exploring the 'Why' 'How' and 'What' questions of research (Maree, 2007). According to Creswell (2007), qualitative inquiry employs human actions from the perspective of social actors themselves.

\subsection{Population, sample and sampling procedure}

The population of this study was made up of all undergraduate students of one university in the Eastern Cape Province of South Africa. Therefore, the sample for this study was limited to some undergraduate students benefiting from these peer academic support programmes. This study utilized a purposive non-probability sampling technique in the selection of the sample. According to De Vos (2005), purposive sampling is based on the judgment of the researcher that a sample has typical elements which contains the most typical attributes of the population. Peer facilitators of the programmes were used as gatekeepers to recommend undergraduate students whom they were of the opinion could provide the necessary information for this study. A total of 10 undergraduate students were selected for this study and they were selected on the basis of the fact that they had more experience on implementation of the programmes. It was ensured that all faculties and genders were represented in the sample.

\subsection{Instruments of data collection: focus group discussions}

The main type of data collection instrument that was used is focus group discussions with the selected sample who had been receiving services from the programmes on a regular basis. Concerning this study, two focus group discussions were held with two groups of ten selected undergraduate students made up of five participants per group. Both genders, different levels of studies, faculties and other parameters were considered in the selection of the participants of the focus group discussions. The two focus group discussions were conducted in Teaching and Learning Centre (TLC) of this university where peer academic support programmes are based. The principal researcher facilitated the discussion with the help of a research assistant.

The focus group discussion began with the principal researcher introducing herself and the research assistant and this was followed by self-introduction of the participants. All the participants then read the informed consent form and each signed to participate voluntarily. While the research assistant was audio-tape recording the discussions, the 
principal researcher was asking guiding questions as well as guiding the process of discussion and also taking down relevant notes.

\subsection{Data analysis}

Data analyses of focus group discussions were manually carried out qualitatively. A general analytical procedure was used in analysing the qualitative data based on the key themes that emerged from the audio-tape recordings. After coding the data and identifying categories and developing themes, main themes and sub-themes were presented to vividly show the perceptions and experiences of the participants regarding the implementation of the peer academic support programmes at this university. In order not to compromise the identity of the participants, all participants were given codes and referred to only by these codes in the paper. The two focus group discussion (FGD) participants were given Student 1 FGD $1-5$ and Student 1 FGD $2-5$ respectively for FGD one and two. Finally, some responses were reported word-verbatim while others were paraphrased in-order to capture expression, phrases and sentences as presented by the participants.

\subsection{Ethical consideration}

The importance of ethical issues lies on the fact that they protect the physical and mental integrity of participants and respect their moral and cultural values as well as their religious and philosophical convictions. Participants in this study were all encouraged to participate voluntarily. The focus group discussion participants signed consent letters to confirm their willing to participate voluntarily. The study ensured anonymity and confidentiality of the participants in data collection, analysis and dissemination. Similarly, the name of the university where this study was carried out is not revealed so as to maintain anonymity.

\section{Findings and Discussion}

The findings are presented according to the biographical characteristics of the participants and the themes that emerged from the focus group discussions.

\subsection{Biographical characteristics of participants.}

The demographic characteristics of two focus group discussions are presented in Table 1. The two focus group discussions were made up of 6 males and 4 females giving a total of 10 participants as seen on Table 1.

Table 1: Biographical characteristics of focus group discussion participants

\begin{tabular}{|c|c|c|c|c|c|c|c|c|}
\hline \multicolumn{9}{|c|}{ Sex } \\
\hline \multicolumn{4}{|c|}{ Male } & \multicolumn{3}{|c|}{ Female } & \multicolumn{2}{|r|}{ Total } \\
\hline \multicolumn{4}{|c|}{6} & \multicolumn{3}{|c|}{4} & \multicolumn{2}{|r|}{10} \\
\hline \multicolumn{9}{|c|}{ Faculty } \\
\hline \multicolumn{4}{|c|}{$\mathrm{FSSH}^{*}$} & \multicolumn{2}{|c|}{$\mathrm{FSA}^{* *}$} & \multicolumn{2}{|c|}{$\mathrm{FMC}^{* * *}$} & \multirow{2}{*}{ Grant Tota } \\
\hline Social work & Psychology & English & Total & Physics & Total & Pub. Adm. & Total & \\
\hline 2 & 4 & 2 & 8 & 1 & 1 & 1 & 1 & 10 \\
\hline \multicolumn{9}{|c|}{ Level of study } \\
\hline \multicolumn{4}{|c|}{ Level } & \multicolumn{5}{|c|}{ Total } \\
\hline \multicolumn{4}{|c|}{1} & \multirow{2}{*}{\multicolumn{5}{|c|}{$\frac{7}{2}$}} \\
\hline \multicolumn{4}{|c|}{2} & \multirow{2}{*}{\multicolumn{5}{|c|}{$\frac{2}{1}$}} \\
\hline \multicolumn{4}{|c|}{3} & & & & & \\
\hline \multicolumn{4}{|c|}{ Total } & \multicolumn{5}{|c|}{10} \\
\hline
\end{tabular}

Table 1 reveals that the majority of the students chosen for these focus group discussions came from the Faculty of 
Social Sciences and Humanities with a total number of 8 out of 10 students representing the different departments. Four students were from the Department of Psychology and 2 each from the Departments of Social Work and English. One (1) student represented the Faculty of Science and Agric from the Physics Department while the other 1 came from Management and Commerce, Department of Public Administration. Perhaps this is still a reflection of the fact that the Faculty of Social Sciences and Humanities is the largest faculty in terms of population at this university. Finally, Table 1 indicates that the focus group discussion sessions were made up of 7 first level (year) students, 2 second level and 1 third level students. This gives a reason for having 8 undergraduate students out of 10 representing the focus group discussion sessions. Given the fact that first year students are new and have many problems trying to integrate themselves into the system, the study had a particular focus on them as they make the most use of the services of these programmes; LWC and SI. This gives a reason why 7 out of 10 students who attended the focus group discussion sessions were first year students.

Table 2 indicates the research questions, the main and sub-themes which emerged during in-depth interviews and focus group discussions with the study participants as well as programme coordinator. These themes formed the basis of the findings of this study. These themes are presented and discussed in the rest of this chapter.

Table 2: Research question, main and sub-themes of the study

\begin{tabular}{|c|c|c|}
\hline Research question & Main themes & Sub-themes \\
\hline \multirow{8}{*}{$\begin{array}{l}\text { What are the perceptions of } \\
\text { students on the } \\
\text { implementation of academic } \\
\text { support programmes? }\end{array}$} & \multirow{5}{*}{$\begin{array}{l}\text { General likeness and } \\
\text { satisfaction }\end{array}$} & Facilitators are friendly and provide one-on-one consultation \\
\hline & & Good assignment and proposal presentations by LWC facilitators \\
\hline & & Facilitators are duty conscious \\
\hline & & $\begin{array}{l}\text { Students accepted to recommend peers to seek help from TLC } \\
\text { because sessions are friendly and interactive }\end{array}$ \\
\hline & & $\begin{array}{l}\text { Passing of assignments and tests after receiving academic } \\
\text { assistance from TLC }\end{array}$ \\
\hline & \multirow{3}{*}{$\begin{array}{l}\text { Most peer facilitators are } \\
\text { undergraduate students } \\
\text { and cannot help effectively }\end{array}$} & Failed assignments that were reviewed by TLC \\
\hline & & TLC does not open its doors on weekend \\
\hline & & Different departments are not fairly represented at TLC \\
\hline
\end{tabular}

\title{
4.2 General likeness and satisfaction of the programmes by students
}

Students were asked during focus group discussions what they like about the programmes. This generated a general likeness of the programmes by the students. The sub-themes include the fact that these programmes are facilitators are friendly and provide one-on-one consultation; good assignment and proposal presentations by LWC; peer facilitators are duty conscious; the students were willing to recommend these services to their peers; passing of assignments and tests after receiving academic assistance from TLC.

\subsection{Facilitators are friendly and provide one-on-one consultation}

In a focus group discussion, students who have been receiving services from TLC were asked to explain what they like about the programmes, and seven out of the ten students in the two focus group discussions reported that they like the programmes. They gave reasons for this including the fact that the programmes involve one-on-one consultations, and also because they get good friendly services. One of the students during a focus group discussion reported as follows:

\begin{abstract}
I like the programmes because it involves one-on- one consultations. Also we get good and friendly services. However, the peer facilitators should be well trained to avoid these criticisms leveled against them. Some are doing wonderful work but others are spoiling the name of TLC and their work. The only thing that I don't like is that there are few peer facilitators and when you bring your assignment here, it takes about a week or more when lecturers normally give two weeks for an assignment to be submitted (FGD 1, participant 2).
\end{abstract}

This is a sign that peer facilitators are welcoming in order to create a good learning environment. Also it can also be noted that it is possible to have one-on-one consultation to enable students express themselves without fear, since some student do not feel free to express themselves in-front of others. This is in support of what Cuseo (2010) affirmed as the approachability of peers which can be very important because they often address sensitive issues with their peers, and feels free to talk than with a faculty member. This is an important aspect which these programmes are promoting 
because; it forces students to meet other senior peers if they have a problem, which is less intimidating.

According to Tinto (1993); Braxton, Sullivan and Johnson (1997) the key to effective academic support for first year includes collaboration between students (peer collaboration). Therefore, it can be rightly assumed that students will feel free to communicate when they meet their peers, especially when it is one-on-one. Contrary to the findings of this study, a peer facilitator at another university said what doesn't work is "creating a classroom environment that is productive and comfortable for all students is an ongoing challenge (Cuseo, 2002). This is something that does not prevail at this university as the peer facilitators have been described by students who seek academic support from them as friendly, encouraging and creating a good learning atmosphere.

\subsection{Good assignment and proposal presentations by LWC facilitators}

Apart from reviewing assignments, LWC facilitators are also required to visit undergraduate classes and make presentations on how to write assignments and proposals for their research projects. In this regard, two of the students who had attended presentations by LWC facilitators affirmed their likeness for this programme, LWC. They stipulated that they cherish the presentations that are done by the facilitators on how to write assignments, do referencing both for books, articles and internet sources as well as how to avoid plagiarism. They maintained that students are benefiting from these presentations conducted by LWC peer facilitators. One of the participants narrated that:

I like the presentations to us on how to write assignments, make citations and arrange references. This has been so helpful especially as we do assignment without lecturers teaching us these techniques. I also like the fact that I have always passed my assignments and tests after I have sought for help from TLC. I also like their positive and encouraging attitude (FGD 2, participant 1).

The university has been plagued by plagiarism problem of late and the presentations on this issue are a welcome one. In addition, the poor presentation of assignments and the incoherent in proposal and referencing methods by many students warrant such presentations. However, care must be taken not to do more harm, if experience postgraduate students are not involved in such presentations. However, from every indication, it is noted that students who visit TLC for help always make something out of it because of the positive and encouraging attitude they get from facilitators.

\subsection{Facilitators are duty conscious}

Another aspect that students liked in the programmes is the fact that the peer facilitators are humble and duty conscious. One student in a focus group discussion said "some of the peer facilitators are duty conscious" (FGD 1, participant 2). This is an indication that most peer facilitators are always on duty despite the complaints leveled against them by some students. Another student added that "I like the fact that the peer facilitators have been taught to be very humble and respectful (FGD 2, participant 3). Therefore the peer facilitators that are chosen by the TLC to help students are accommodative such that students can always approach them without fear or intimidation.

Facilitators sometimes rush to consult students at TLC or they go to classes and campaign for students to bring their problems to them at TLC. The TLC does encourage this marketing strategy whereby facilitators campaign for students because it is a way of letting students utilizes their services. However, the disadvantage is that some of the facilitators do so in order that they should have sufficient number of students and hours to claim at the end of the month otherwise they will not be able to claim enough for the month. Therefore, being rude or harsh to students would not pay the facilitators who will lose getting students leading to low pay at the end of the month.

\subsection{Peers to seek help from TLC because sessions are friendly and interactive}

Students were also asked if they will advise their fellow peers to seek services from TLC, they all agreed that they will always advice their friends who are facing academic problems to come to TLC for help. One student even confessed that it will be a big lie if a student complains that facilitators are not helping. The student said that:

Obviously, I will recommend my peers to come here for academic assistance or services. There is no way that one can refuse not benefiting something from here. It will be a big lie for anyone to say that because no matter what you are told here, you always learn something (FGD 2, participant 1). 
Another student also supported the colleague by saying that:

Yes I will advise my friends to come to TLC for help, because it has been helping us. It is also helpful because here there is one-on-one consultation (FGD 2, participant 3).

This is a suggestion that even though there are complaints that the programmes are not liked by some, students are benefiting gradually from these programmes. During focus group discussions, the participants also agreed that the sessions organized by facilitators are friendly and very interactive in nature. Therefore, the students are able to express themselves freely and exchange ideas on topics or issues that they did not understand in class. It has been shown that students are more likely to discuss their problems with peers and feel less intimidated by other students (Sonntag, 1993).

\subsection{Passing of assignments and tests after receiving academic assistance from TLC}

Five of the ten students who participated in the two focus group discussions maintained that they were satisfied with the services provided by TLC peer facilitators. There is nothing good for students passing with good marks in their assignments and tests. Whoever makes students to pass their assignments and tests will most likely be loved and admired by the students. On the aspect of whether students were satisfied with how their problems presented at TLC were being solved, the five students agreed that they were satisfied with how their problems are being solved. For the satisfied students, they said everything was fine because they have been passing the assignments that are being reviewed by TLC facilitators and also passing their tests. One of the responses by one student was as follows:

Yes I am satisfied because I usually pass my assignments and tests whenever I am helped from here. She added that the problem with some students is that sometimes they want the peer facilitator to do the corrections for them. More-so, many bring their assignments and want them almost immediately forgetting to know that the facilitators are students and have their own academic work to do just as they (FGD 2, participant 1).

This participant was very conscious of the complaints leveled against the TLC and its services when she reported the mistake made by some students who want their problems to be attended to without delay and without taking into consideration that these facilitators are students like themselves with their own academic problems and workload. The most common mistake that is made by most students is that they want peer facilitators to do the work for them. They believe that if they don't do the work for them, they should at least tell them the answer to the question so that they simply write it down. This explains the reason why the above student cautioned about seeking solutions with immediate effect without due consideration that the facilitators are students like themselves. The role of peer facilitator in any teaching and learning environment as propounded by modern technique of teaching is to facilitate and not to teach. However, there is still a mixture of teaching and facilitation given the poor socio-economic status of the students at most of the previously disadvantaged universities. The passing of assignments and tests shows that there is a mutual benefit that accrues from peer facilitation. Higher education research on peer teaching/learning consistently indicates that both the peer learner and the peer teacher (facilitator) experience significant gains in learning as a result of their collaborative interaction (Cuseo,2002).

\subsection{Most peer facilitators are undergraduate students and cannot help effectively}

A general issue or concern that was raised by both students during focus group discussions and programme coordinators was that most facilitators, especially SI leaders were undergraduate students who were also overwhelmed with their own work. Therefore, these facilitators are unable to effectively help other students who faced academic problems. Consequently, the sub-themes failing to past assignments that are reviewed by TLC consultants, general dissatisfaction with TLC services, recommending TLC to open its doors on weekends and towards examination periods; and also engaging different departments so that they are fairly represented among the SI and LWC.

\subsection{Failed assignments that were reviewed by TLC}

The findings of this study according to the two focus group discussions also indicate that five students were of the opinion that they were not satisfied with the services provided by peer facilitators. These five recounted the incidents when their assignments have been reviewed by TLC and they still scored low or failed marks whereas some who did not 
bring their assignments to TLC passed well or scored high marks. Some of them even refused to neither come to TLC nor encourage their peers to take their assignments or academic problems to TLC. One of the focus group discussion participants revealed that:

I'm not very satisfied as sometimes I am not properly helped because some of the peer facilitators are not better than me. I have also heard students who have vowed not to come to TLC because they couldn't do well in assignments they submitted here for review. They would prefer to go to other senior students for help (FGD 2, participant 3).

Perhaps this might be in line with what one of the programme coordinators pointed out. According to the facilitator:

\begin{abstract}
I am satisfied but to some extent the facilitators with Honours degree sometimes face challenges especially when it concerns reviewing assignments. I thought of not recruiting them, but again it will still be a challenge in that I will never have experienced facilitators (Coordinator 2).
\end{abstract}

Some other students complained that their assignments are always having numerous corrections which are discouraging. There was a probe for the student to explain the reasons for their assignments always having many corrections and the student responded that may be it is because the facilitators are not from our faculty. They reported that some of the facilitators also have a problem of saying they don't know. Another student concurred that many students complained that the help they get from TLC regarding their assignments do not go far enough to earn them good marks. It may be assume that some of the facilitators that are recruited are not well equipped on the strategy of implementing the programmes or are less experienced as revealed in the biographical section of this chapter. All these complaints are a warning that there is a problem with the way peer facilitators (LWC) review assignments. It might be assumed that most of them need more training in other to be equipped on how to review assignments. It is also a clue that facilitators from different faculties review assignment for students who are not from the same faculty. According the theory of retention by Tinto (1975), a student will be more likely to retain or continue studies if there is a favourable prevailing academic and social environment of the institution. In other words, the student will be motivated to learn if he/she is passing the courses well. On the contrary, it is not the case with these students. It might be assumed that these students are not being motivated due to the low marks they get when they are helped by TLC peer facilitators.

\title{
4.10 TLC does not open its doors on weekend
}

A few students complained that TLC does not open its doors on weekends to enable students who were busy during the week to seek for academic help facing them. Two students disliked the programmes for the reason that some peer facilitators are not well equipped and the venue is always close when they desperately need them during examination periods. One student complained bitterly that:

I don't like the fact that sometimes the PASS venue is closed at a crucial time that students need academic support from peer facilitators most. This is especially towards the approach of examinations (FGD 2, participant 4).

Similarly, another student supported this by saying that:

I dislike the fact that sometimes peer facilitators can't help during examination periods, they will say I don't know this and that, why are they employed for if they can't help us? (FGD 1, participant 3).

It is likely that the Peer Assisted Student's Services venue (PASS) is always closed during examinations period because of undergraduate students working in the programme $(\mathrm{SI})$. This may be that it is a strategy to let them also go and prepare for their own examinations as well, rather than just serving students without helping themselves. This closure of TLC is not only unique to this university but to most universities in South Africa. Accordingly, Kadalie (2013) confessed that "South African universities shut down their doors during the long vacation providing students with minimal support and incentives to boost their academic experience". This idea is in line with what most students complained about. It is an indication that during examinations period, students find it difficult to get help from TLC which is a problem.

\subsection{Different departments are not fairly represented at TLC}

For effectively academic assistance to be provided to students by the TLC peers, it is necessary that peer facilitators who 
attend to students should come from the same disciplines or departments (facilitator and student with academic problems). This was one of the issues brought up by students whose departments or disciplines are not represented at TLC and are therefore attended by peer facilitators from other disciplines. One of them indicated that:

I'm not satisfied at all because those who help me here sometimes make it more confusing especially with some law courses that we are doing. There is no specific facilitator for law at TLC which is a problem for law students because there is neither an SI or LWC facilitator servicing law students. There is also no faculty of education represented here as a supplemental instructions leader. However, education has a few LWC facilitators (FGD 1, participant 3).

Some peer facilitators agreed with the above concern that some disciplines are not represented and they are forced to help those students without a good knowledge of their disciplines. Consequently, there is bound to be confusion in the way other peer facilitators from other department attempt to help students solve their academic problems. This is in line with what one of the peer facilitators commented about. According to the peer facilitator:

Sometimes we review assignments that are not from our disciplines and as such, we are not very conversant with the subject matter and style used in such disciplines. We therefore confuse the students the more by attempting to help then when we can't actually help them in the real sense of it (Facilitator 2).

The above student was a law student and the faculty of law has a unique way of reporting cases and doing referencing style which most often is the footnoting and endnotes. Peer facilitators from other faculties such as science and agriculture, social sciences and humanities, education and management and commence are not conversant with these law uniqueness, hence the confusion law students are set in when they are attempted to be helped at TLC. Nonetheless, the faculty of law is based in a different campus. However, there are students from other disciplines who are doing law elective courses and they need to be assisted by peer facilitators who are law students at TLC which is not the case. According to Tinto's theory of students' departure (1993), this category of students have not yet been integrated into the university system because their expectations and aspirations which have not been meant by the TLC. This can affect their outcome such as degree attainment leading to dropout or low throughput rate resulting from poor implementation of students' academic peer academic support programmes.

\title{
4.12 Ways of improving the implementation of TLC programmes
}

Suggestions were sought on the improvement of the implementation of TLC peer academic support programmes at this university and a variety of responses were got from students, coordinators and facilitators. Most of the proposals were based on the fact that all facilitators should be postgraduate students and they should be well trained in their respective departments on how to review assignments and other related TLC support services. Apart from postgraduate students proposed for recruitment, they suggested that more facilitators should be recruited; at least two per department. One of the students made a lengthy proposal on how TLC could better implement its activities vis-à-vis students. She commented that:

\begin{abstract}
I also think that if postgraduate students are those to be recruited as peer facilitators, it would be better for students seeking academic help from TLC. It is my humble suggestion that PhD peer facilitators should be allocated to help all other students from first year PhD downward to first year students. Masters peer facilitators should also be assign to help first year master students and right down to first year students. Therefore, masters peer facilitators must not be assigned to help PhD students whatsoever. Similarly, Hons peer facilitators should be helping only undergraduate students and not fellow Hons and masters. Finally, final year peer facilitators should be assigned to help only students who are below them in their year of study (FGD2, participant 3).
\end{abstract}

According to the above participant, the postgraduate students recruited should only be allowed to provide academic support to students who are below them in terms of year or level of study. In this case, there will be no inferiority complex exhibited by lower level students attending to senior or the same year or level students. Similarly, another student echoed the above sentiment regarding the recruitment of only postgraduate students to serve as peer facilitator. According to the student:

I support the fact that only postgraduate students should be recruited and trained as peer facilitators. If this was the case, many of these complaints will not be there. We might still have some but not as many as with the case where underprepared undergraduate are destroying the reputation of TLC with their poor and ineffective services as well as 
limited knowledge of the contents of what students expect to learn from TLC (FGD 1, participant 5).

Another suggestion from some peer facilitators is the a call for a review of how much they are remunerated as compared to tutors, especially given the type of work they are undertaking at TLC. They insisted that as a matter of social justice, there should be equal pay for equal work done irrespective whether one is a tutor or a TLC facilitator, be it SI or LWC. One of the facilitators suggested as follows:

Current facilitators must market themselves very well. Perhaps the peer facilitators are not performing well because some of them complain that they earn less than a thousand rands per month when tutors are earning almost twice what they earn at TLC (FGD 1, participant 3).

Poor remuneration at this university is a huge challenge and this has led to the non-retention of good peer facilitators who opt for less stressful tutor work in their respective departments or doubling of positions as tutor and peer facilitator in order to earn better wages at the end of each month. This remuneration is not only a problem for peer facilitators but also a problem for staff, many of whom end up leaving the university for 'greener pastures'.

\section{Conclusion}

There are many peer facilitators who are from the Science and Agriculture and the Faculty of Social Science and Humanities. The most likely conclusion that can be drawn is the fact that most departments are not fairly represented at the TLC and this is disadvantageous to those who are not having discipline representatives. As such their assignments or academic problems are handled by those academic support peers who are from different disciplines; hence the poor performance by some of the peer facilitators. Also most of them are female students as well as undergraduate students serving as SI leaders. There are many disadvantages of this category of peer facilitator serving students. In addition most of them are less experienced after only being recruited at the beginning of 2013. These undergraduate peer facilitators do have many challenges including their own personal academic and social obligations or imperatives and this is posing a huge challenge to the implementation of the SI programme run by TLC at this university.

The use of undergraduate students as peer facilitators has drawn much criticism from the students who perceive the implementation of the programmes in negative terms on many fronts. However, there are probably two issues here, one is that some of the students' complaints are simply as a result of laziness while there is also poor review assignments by inexperienced facilitators as well as those who are not from the same department or discipline as the student whose assignment is reviewed. The problem of reviewing of assignments from any department by any peer facilitator emanate from the remuneration system that is adopted by TLC which is that of claiming. In order to have enough hours to claim at the end of the month, these peer facilitators are forced to review assignments from whichever disciplines irrespective of whether it is from their own disciplines. Therefore, poor remuneration and the claiming system which is different from that practiced in most departments with tutors have led this problem. It is a problem if facilitators are not sufficiently, especially the most experienced ones. This has pushed some to go for multiple jobs at the TLC and departments serving as facilitators and tutors at the same time because they want more money to finance their studies and solve their socio-economic problems. The situation here is that the University policy stipulates that students should not work more than 24 hours per month. While some benefits from double jobs, others for fear of this university stipulations are forced to abandon one job which obviously is TLC in preference for a steady tutor's stipend. This explains the reason why TLC keeps on replacing facilitators throughout the year.

There are enough peer academic support programmes put in place to help improve students' academic performance at this university, which are Language and Writing Consultant (LWC) and Supplemental Instruction (SI) programmes. However, these programmes are not being fully utilized by the students. The under-utilisation of the TLC services can not only be blamed on students but also the fact that most department or faculties do not encourage their students to make use of the services offered by TLC. There is no clear distinction because a peer facilitator and a tutor and as a result, students and academics are confused and see TLC facilitators as a duplication of the work of tutors. Academic support programmes are very important in enhancing student's academic performance especially with students from previously disadvantage universities. Therefore without the adequate support of students, facilitators, coordinators and lecturers from different departments, it will be difficult for these programmes to achieve their objectives. 


\section{Recommendations}

The findings of this study reveal that there are numerous challenges facing the effective implementation of LWC and SI programmes at this university. Therefore, these challenges could be serious obstacles to achieving the high retention and throughput rates which are the targets of the TLC academic support programmes. In order for peer academic support programmes at this university to operate successfully, the following are recommended:

1) All faculties should be represented and those large faculties like Science and Agric and Social Sciences and Humanities should have at least two peer facilitators each to help students.

2) All facilitators, especially those who possess a certain level of experience, should be given incentive as a way of motivation and also to encourage them to stay in the programmes. More-so, there should sufficient remuneration of TLC peer facilitators on parity with tutors and they wages should also be considered for inflationary adjustment annually.

3) All departments should be involved in the implementation process. The departments should encourage their students to seek help from TLC programmes. This can only be achieved if departments have buy-in and the TLC should ensure that this is possible through canvassing for their involvement.

4) Peer facilitators should all be post graduate students since they are not restricted to do any class work and are mature in handling academic problems, especially for the undergraduate students. This will also enable TLC to open its doors even during examinations and holiday periods.

5) Students and lecturers should be educated on the differences between a tutor and an SI leader. This will eliminate the current confusion that lingers in the mind of students and academics about these two types of peer facilitators.

\section{References}

Archer, A. (2010).Challenges and potentials for Writing Centres in South Africa tertiary institutions South Africa Journal of Higher Eucation, 24(4), 495-510.

Bally, J. M. (2007). The role of nursing leadership in creating a mentoring culture in acute care environments. Nursing Economics, 25(3), 143.

Boughey, C. (2010). Academic development for improved efficiency in the higher education and training system in South Africa. Pretoria: DBSA.

Braxton, J.M., Sullivan, A. S.,and Johnson,R.M.(1997). Appraising Tinto's theory of college student departure. In J.C Smith(ed). Higher education: Handbook of theory and research, Vol 12 ( pp107-164). New York: Agathan.

Chabaya, O.; Rembe, S.; Wadesango, N. \& Muhuro, P. (2010). "Assessment of first year female students' experiences in historically male-dominated subjects in relation to retention and persistence in Higher Education from a cultural capital perspective" (Unpublished).

Cloete, N. \& Bunting, I. (2000). Higher Education Transformation: Assessing performance in South Africa. Pretoria: CHET.

Cresswell, J. W. (2007). Research Design: Qualitative, Quantitative and Mixed Methods Approaches (2nd Ed). Thousand Oaks: SAGE.

Cuseo, J. (2010b). Peer Leadership: Situation-Specific Support Role. E-source for college Transitions, 7 (6), pp. 4-5.

Cuseo, J. B. (2002). Igniting student involvement, peer interaction, and teamwork: A taxonomy of specific cooperative learning structures and collaborative learning strategies. Stillwater, OK: New Forums Press.

Department of Higher Education (1997). The White Paper on Higher Education. Pretoria: Department of Higher Education.

Department of Higher Education and Training (2012). Foundation Provision in Ministerially approved programmes. Pretoria: Department of Higher Education and Training.

De Vos, A. S. (ed.) (2005). Research at Grass Roots: For the social sciences and human services professions. Pretoria: Van Schaik Publishers.

Fisher,R (1995). Teaching Children to learn United Kingdom: Stanly Thornes (Ltd).

Fourie, M. and Alt, H. (2000). "Challenges to Sustaining and Enhancing Quality of Teaching and Learning in South African Universities", Quality in Higher Education, Vol. 6, No. 2, pp. 115-124.

Jansen, L. (2012). "High drop-out rate may doom pupils", IOL News, August 27. Retrieved from htpp://iol.co.za/news/politics/high-dropout-rate-may-doom-pupils-1.1370109, August 28, 2012.

Kaburise,P.(2010) Linguistic Meaning-Creation Strategies of potential Univen students. Unpublished research report.

Kadalie, R. (2013). "What's wrong with our universities", Politicsweb, August 27. Available from www.politicsweb.co.za/politicsweb/view /politicsweb/en/page71619?oid=40093 (Accessed August 29, 2013).

Makura, A.; Skead, M. and Nhundu, K. (2011). "Academic development practices at Fort Hare University: An epitome of University access", Research in Higher Education Journal, Vol. 12, pp. 13-22.

Maree, K. (ed.) (2007) First Step in Research. Pretoria. Van Schaik Publisher.

Martin, D. C. and Arendale, D. R. (eds) (1994). "Supplemental Instruction: Increasing achievement and retention", New Directions for 
teaching and learning, №. 60. St. Francisco: Jossey-Bass.

Matomela, D. (2010). "Pass rates for first year varsity students decline", Education Report. The Herald, February 3. Retrieved from http//www.theherald.co.za/article.aspx?id= 526814, February 3, 2010.

McInnis, C.; James, R. and Hartley, R. (2000). Trends in the first-year experience in Australian universities. Department of Education, Training and Youth Affairs, Canberra. Retrieved, from http://www.dest.gov.au/archive/highered/eippubs/eip00_6/fye.pdf, 18 January 2010.

Organization for Economic Cooperation and Development (OECD) (2008). OECD in Figures (20th anniversary edn.). OECD: Paris. Retrieved from http//www.oecdbookshop.org. June 10, 2011.

Peterson, A. and Arends, F. (2009). Teacher graduate production in South Africa. Cape Town: HSRC.

Reyes, R. (2007). Struggle, Practice, and Possibility: Lessons learned from marginalized women of Mexico descent in their first year of college through the CAMP program. Equity and Excellence in Education, vol. 40: 218-228.

Skead, M. (2006). The supple in supplemental: making SI work in a developmental context. Paper presented at the fourth International SI Conference, Malmo, Sweden.

Sonntag, G. (1993). Information Technology Peer Counsellors: A Proposal. Lottery grant proposal. CSU: San Marcos.

Subotsky, G. (2003). "Private Higher Education and Training". In HSRC Human Resources Development Review. Pretoria: HSRC.

Tinto, V. (1975). Drop-out from higher education: a theoretical synthesis of recent research. Review of Education Research, 45, pp. 89125.

Tinto, V. (1993). Leaving College: Rethinking the Causes and Cures of Student Attrition. (2nd Ed). Chicago: University of Chicago Press.

Twalo, T. (2008). The enhancement of students' performance at Fort Hare University through the Language and Writing Advancement Programme. Journal for Language Teaching, Vol. 42, No.1: 137-151. 